determining carbohydrates as suggested by Bransby, Daubney \& King (1948). The problem reaches its most acute form in foodstuffs used by some primitive peoples, e.g. in a specimen of baobab flour which we recently examined, the carbohydrate by difference was $76 \%$, whereas the glucose calculated from the copper-reducing power after hydrolysis was $33 \%$. The exceptionally high pectin content accounted for much of the difference.

In this short review it has only been possible to refer to a few of the problems in the administration, including the framing of laws relating to foods, but it must be obvious that much remains to be done not only by the legislature but also by the Scientific Advisory Services to the Legislature before men and animals are adequately protected.

\title{
REFERENCES
}

Adams, C. A. (1 951 ). Brit. F. Nutrit. 5, 367.

Alcock, R. S. (1946). Analyst, 71, 233.

Bransby, E. R., Daubney, C. G. \& King, J. (1948). Brit. F. Nutrit. 2, 89.

Chatfield, C. (1949). Nutritional Studies, no. 3. Washington: Food and Agriculture Otganization of the United Nations.

Chibnall, A. C., Rees, M. W. \& Williams, E. F. (1943). Biochem. J. 37, 354.

Fryd, C. F. M. \& Kiff, P. R. (1951). Analyst, 76, 25.

McCance, R. A. \& Widdowson, E. M. (1946). Spec, Rep. Ser. med. Res. Coun., Lond., no. 235, 2 nd ed.

Meihuizen, S. H. (1929). Chem. Weekbl. 26, 417.

Miller, L. \& Houghton, J. A. (1945). F. biol. Chem. 159, 373.

Reith, J. F. \& Wansink, E. J. (1947). Chem. Weekbl. 43, 803.

Taylor, G. (1948). The Fertilisers and Feeding Stuffs Act and some Analytical Implications. Thirtieth Streatfield Memorial Lecture. London: The Royal Institute of Chemistry of Great Britain and Ireland.

Willits, C. O., Coe, M. R. \& Ogg, C. L. (1949). Y. Ass. off. agric. Chem., Wash., 32, 118.

Woodman, H. E. \& Evans, R. E. (1938). F. agric. Sci. 28, 43.

\section{The Toxicological Aspects of Food Adulteration}

\section{By J. M. Barnes, Medical Research Council, Unit for Research in Toxicology, Carshalton, Surrey}

\section{Definition of toxicity}

For the present purposes the definition of adulteration will be extended to include substances added to food for a specific purpose as well as those used as substitutes for proper nutrients. It will include also materials that find their way into food as a result of modern agricultural practices.

A substance is usually considered to be toxic if it produces some direct unfavourable effect on a normal metabolic process. In some instances the disturbance has been quite clearly defined and the nature of the 'biochemical lesion' so produced can be identified (Gavrilescu \& Peters, I93 I). In others injury to a vital organ results directly or indirectly from the action of a poison. Finally, a substance may be considered toxic because it is carcinogenic.

In considering the possible toxic effects of chemicals in food, their more indirect effects must not be neglected. They may act by altering the natural materials of the 
food itself as exemplified by the reaction between nitrogen trichloride and wheatflour protein. They may interfere with the function of the intestinal tract directly as, for example, by disturbing mucous secretion or indirectly by altering the dispersion of the intestinal contents and so affecting absorption. They may immobilize or prevent the absorption of important elements such as vitamins or mineral salts that are present only in small quantities.

\section{Mode of investigating toxicity}

Instead of attempting to mention the toxic properties of all synthetic chemicals used in the food industry, an outline will be given of the methods of investigation that are available, and a few examples will be chosen to illustrate the general problem.

From what has been said above, it is obvious that a simple test of acute toxicity will be of limited application for investigating the effect of chemicals used in food. It is unlikely that any material with a demonstrable, acute toxic effect when administered by mouth in reasonable doses to laboratory animals would ever be recommended for use in food. The assessment of possible carcinogenic properties is a problem quite outside the writer's experience, but on general grounds it would seem undesirable to use any material in food that has been shown to have a carcinogenic action in any species of animal.

Studies of chronic toxicity are usually made by including the test material in the diet of laboratory animals for long periods. Given the space and equipment, together with a few well-trained animal attendants, it is relatively easy to carry out such feeding procedures. The problem of assessing the results and converting the procedure into a proper experiment is quite another matter. In many instances the only index that can be used is the growth rate of the animals, their rate of reproduction and the histological appearances of the organs at the end of the feeding test. Weight changes and degree of fertility are relatively simple to determine. Evidence of histological changes in the important organs can be obtained only after careful examination of many histological preparations by a pathologist who is familiar with the variations normally found in the tissues of the particular animals being used. It is perhaps worth mentioning a few of the practical limitations to this kind of work. Considerations of space and economy exclude the use of any but small laboratory animals for such experiments. A homogeneous population must be used, and a species chosen that is not unduly susceptible to laboratory infections. The animals must be omnivorous. It can be said, therefore, that the results of long-term feeding experiments will, with few exceptions, be derived only from data obtained from rats. It would appear desirable to continue to administer the compound for as long as possible, but if the rat population is allowed to grow old structural changes in the tissues due to disease and advancing age will appear and make the task of the pathologist more difficult, if not impossible.

To determine the direct toxic effects of a compound it would be desirable to trace the history of the substance from the moment it entered the animal and to determine how much was absorbed and how much excreted and the distribution and metabolism of the compound in the tissues. For a single substance such a problem might be the work of a lifetime for a chemist and biochemist. Usually the possibility does not 
exist of even attempting to carry out such a programme because there is no method for estimating small quantities of the material in the tissues. To attempt to determine the metabolic disturbances produced in the host by the presence of a foreign chemical substance would again prove a very large undertaking. If the indirect effects are considered, it might involve, for example, complete mineral-balance studies or vitamin estimations to try to determine whether or not the presence of the suspected material in the alimentary tract was interfering with the nutrition of the animal.

Whenever any information is acquired from an experiment of this type on animals, the findings have to be interpreted in terms applicable to man. The difference in the reaction of various species to drugs and chemical compounds of all kinds is only too well known to pharmacologists and physiologists. The problem of individual susceptibility is one that is particularly well recognized in man and cannot be disregarded. Before 1934 the condition known as agranulocytic angina was a clinical entity commonly fatal and of unknown origin though usually associated with a severe septic sore throat. Then an association was discovered between the incidence of the disease and previous prolonged ingestion of amidopyrine. Since that time, of course, many other drugs have been shown to be capable of producing the particular syndrome, but the drug in question has always proved to be quite harmless to the great majority of people who take it and kills only the few susceptible ones. Is it not possible that there are clinical conditions to-day that are in a position comparable with that of agranulocytic angina 20 years ago?

\section{Examples of problems in toxicity}

It is of interest to consider some examples of chemical substances found in food that are deliberately or accidentally included.

Methyl cellulose is used as a stabilizing agent, especially in ice-cream. It is devoid of any nutritive value. Rats have been given almost as much as $0.5 \mathrm{~g} ., 2.5 \mathrm{~g}$. $/ \mathrm{kg}$. bodyweight, daily for 9 months. 'Their growth rate was unaffected and the tissues were normal on histological examination (Deichmann \& Witherup 1942-3). Experiments on man have confirmed the observation that methyl cellulose is not metabolized and that none of the methoxy groups are split off and excreted as methyl alcohol or formaldehyde (Machle, Heyroth \& Witherup, 1944). Because it is so inert, however, it acts as an excellent laxative, and a dose of $10 \mathrm{~g}$., or about $0.2 \mathrm{~g}$. $/ \mathrm{kg}$. body-weight, will double the weight of stools produced by a human subject (Tainter, 1943). Such a laxative effect might not always be desirable, but otherwise the material is probably harmless.

Polyethylene glycols of molecular weight from $125^{\circ}$ to 3600 have been included in foods as well as in cosmetics. Again, the evidence from experiments with rats is that large quantities, as much as $20 \mathrm{~g}$. $/ \mathrm{kg}$. body-weight daily, may be ingested for 3 months without producing ill effects (Smyth, Carpenter, Shaffer, Seaton \& Fischer, 1942). Experiments with dogs have shown that they do not depolymerize the compound into the poisonous ethylene glycol but excrete it unchanged (Shaffer, Critchfield \& Carpenter, 1948). The same workers have shown that the same is true for rabbits and man (Shaffer, Critchfield \& Nair, 1950). In the less pure preparations of the polymers, however, ethylene glycol may be included, and it is essential that material for use in 
food must conform to the highest standards of purity. Smyth, Carpenter \& Weil (1950) have reported that pure preparations of polyethylene glycols have a lower toxicity than those that they tested and reported on earlier. The need to conform to the highest standards of purity will apply to all chemicals used in food, and is possibly the most important factor that should be controlled.

A number of preparations containing polyoxyethylene sorbitan monostearate have been used as anti-staling agents in bread. When incorporated into the loaf at a rate of $0.2 \%$, they prevent the crumbling of unwrapped bread and preserve crumb softness (Coppock, 1950). In America, where other ingredients are included in the loaf, higher proportions of the anti-staling agent must be used. It is obvious that any compound deliberately added to bread in this way must be completely non-toxic in every sense of the word.

Polyoxyethylene sorbitan monolaurate has been given to rats as from 0.5 to $2.0 \%$ of their diet for their lifetime without apparently upsetting them, and a daily dose of I $g$. has been given to four monkeys, again without producing any obvious toxic reactions (Krantz, Carr, Bird \& Cook, 1948). When, however, the monostearate was incorporated as up to $25 \%$ of the diet of young rats, they developed nasal haemorrhages, gangrene of the tail and legs, severe diarrhoea and vesical calculi. At a level of $12.5 \%$ the rats were unaffected (Harris, Sherman \& Jetter, 1950). Though it is easy to dismiss these experiments because of the excessive quantity administered, consideration of these two reports raises the question of how to decide on a margin of safety. On the basis of the experiments just mentioned, it would seem that a tenfold reduction of a dose obviously poisonous for the rat results in an amount that can be ingested indefinitely without harm. What are the proper margins of safety to allow in calculating a safe amount for man when the only available information is the toxic and safe levels for rats? The issue with the polyoxyethylene sorbitans is further confused by a report of the effects on hamsters of ingesting polyoxyethylene monostearate at a level of only $5 \%$ in the diet (Schweigert, McBride \& Carlson, 1950). Some of the animals died, and their growth was less than that of animals given lard. In a subsequent paper the histological findings are described (Wang, McBride \& Schweigert, 1950). Some of the statements made are very curious, such as that describing erosion of the mucous membrane of the intestine as being 'more intensified on one side, presumably that in contact with the intestinal contents'. Although in the text the kidney lesions are dismissed as of no significance, the photomicrograph of a section of a kidney from one of the animals shows a remarkable degree of widespread damage throughout the organ. The evidence presented may be dismissed as of no importance at all, and yet the deaths reported among the animals given polyoxyethylene monostearate may have been attributable to its presence.

Saccharin is still the most popular artificial sweetening agent, but recently others have been produced; 1 - $n$-propoxy-2-amino-4-nitrobenzene has 4100 times the sweetening power of cane sugar, and reports from Holland where it was first produced claimed that it was not toxic. It is, however, a local anaesthetic, and a recent report states that when rats were fed with it, it led to changes in the thyroid gland and urinary tract and the rats developed hepatomas (Fitzhugh \& Nelson, 1950). In the 
same experimental conditions saccharin proved apparently harmless. Such evidence should be enough to condemn the material as unsuitable for inclusion in any food or drink.

The possible dangers from the use of carcinogenic dyes to colour food needs no stressing, and reference should be made to the work of Cook (1948) and of Kirby \& Peacock (1949).

Within recent years new chemicals have been used in increasing numbers to treat growing crops and stored food products. New and poisonous insecticides are being developed in large numbers. Insecticides and pesticides are being used extensively to rid food factories and food shops of insects and other pests. Fortunately some of the most poisonous of them are also chemically unstable and rapidly disappear after being applied to food crops. Others, however, may persist for long periods of months or years, and resist the action of moderate heat. Dichlorodiphenyltrichloroethane (DDT) has been the subject of many investigations. Laug, Nelson, Fitzhugh \& Kunze (1950) have claimed that rats given as little as 5 p.p.m. DDT in their diet show histological changes in their livers. The significance of the changes is, however, open to serious doubt since the fixative used was not one that would readily permit fine cytological differences to be recognized and the photomicrographs provide no support for the claims made in the paper. DDT has, however, another property shared by some, but not all, of the chlorinated aromatic hydrocarbons used as insecticides; it accumulates in the fat of animals even when the amount in the diet is as little as I p.p.m.

Laug, Prickett \& Kunze (1950) have examined samples of human milk and fat removed from members of the general population. No appreciable amount of DDT was found in the samples of milk, but up to 34 P.p.m. was recovered from the fat of some patients. It is difficult to venture an opinion as to whether or not the continued presence in human tissues of this compound of known biological activity will be quite harmless. Tauber \& Hughes (1950) found that in the rat the highest concentrations of DDT were in the lipids of the ovary, and they suggest that the observation may explain why it was the second generation of rats that was affected in breeding experiments with rats given DDT (Fitzhugh, 1948). It is extremely difficult to know what to conclude about the risks likely to accrue to mankind from ingesting food contaminated with DDT. In a period when there are food shortages in many parts of the world, hypothetical risks such as these have to be weighed against real risks of undernourishment if pests are allowed to reduce harvests and spoil food.

More recently another group of compounds has been introduced to discourage the sprouting of potatoes kept in store for consumption at the end of the season. Tetrachloronitrobenzene is an effective sprout depressant, and it has been shown to possess little toxicity (Buttle \& Dyer, 1950). Isopropylphenylurethane also has been shown to be effective for the same purpose (Rhodes, Sexton, Spencer \& Templeman, 1950). It is difficult to believe that any chemical applied in small quantities to the exterior of unwashed and unpeeled potatoes before they are put into clamps for storage will ever find its way into the interior of the human body. Nevertheless, potatoes are a staple article of diet for the whole population, and their absolute freedom 
from chemicals seems desirable. In considering the case of isopropylphenylurethane, it should be remembered that certain of the urethanes are potent carcinogens.

\section{General considerations}

From what has been said it is clear that it is no easy task to design an experimental method for determining whether a substance will be harmless if added to the diet of man. Though a certain amount of evidence can be obtained from animal experiments, the interpretation of the results must still remain a matter of personal opinion. Except for those compounds like the insecticides that find their way into food chiefly by accident, there is very little sound experimental evidence for condemning the use of any of the materials added deliberately to foods on the grounds of their toxic properties. It is unlikely that anyone will ever press for the use of a substance that can be shown by experiment on animals to possess any acute toxicity when administered in reasonable doses.

The problem of determining the effects of small quantities of a substance when ingested over a number of years, is almost insuperable unless only one particular aspect of toxicity is studied, such as carcinogenic action. When the only answer that can be gained from toxicological investigations is that of 'not proven', the decision as to whether or not a substance is to be allowed to appear in food must be based on other considerations.

On general grounds it seems desirable that the food available, particularly for urban populations, should be as nearly as possible in its natural state. Minerals and trace elements are then consumed in the same nicely balanced porportions in which they occur in living plants or animals. 'The production of foods which more and more resemble pure carbohydrate, pure protein or pure fat seems an undesirable trend. To add substances that may exaggerate or depress the absorption of certain ingredients may serve to upset still further the balance of the natural nutrients. One may conclude, therefore, that the problem of the adulteration of food by chemical substances will come to lie within the field of nutrition rather than in the more strictly limited one of toxicology. Nevertheless, it will still remain true that any substance added to food must display no readily demonstrable toxicity for animals and must satisfy rigorous standards of purity.

\section{Summary}

I. The meaning of the terms adulteration and toxicity is defined.

2. Consideration is given to the methods available for determining the toxicity of substances and the difficulties of deciding whether a substance can be considered harmless are emphasized.

3. A few examples of chemical substances found in food to-day are given to illustrate the different problems discussed earlier.

4. It is concluded that all chemical substances added to food must be devoid of any demonstrable acute toxicity towards mammals and must satisfy strict specifications of purity.

5. The decision as to whether or not a substance satisfying these conditions should 
be used in food must rest on considerations other than those of its toxicity. Such considerations may be within the field of nutrition rather than the narrower limits of toxicology.

\section{REFERENCES}

Buttle, G. A. H. \& Dyer, F. J. (1950). Y. Pharm. Pharmacol. 2, 371.

Cook, J. W. (1948). Brit. \%. Nutrit. 1, 245.

Coppock, J. B. M. (r950). Y. Sci. Food Agric. 1, 125.

Deichmann, W. \& Witherup, S. (1942-3). F. Lab. clin. Med. 28, 1725.

Fitzhugh, O. G. (1948). Industr. Engng Chem. 40, 704.

Fitzhugh, O. G. \& Nelson, A. A. (1950). Fed. Proc. 9, 272.

Gavrilescu, N. \& Peters, R. A. (1931). Biochem. F. 25, 2 I 50.

Harris, R. S., Sherman, H. \& Jetter, W. W. (1950). Fed. Proc. 9, $36 \mathrm{r}$.

Kirby, A. H. M. \& Peacock, P. R. (1949). Glasgow med. J. 30, 364.

Krantz, T. C. Jr., Carr, C. J., Bird, J. G. \& Cook, S. (1948). J. Pharmacol. 93, 188.

Laug, E. P., Nelson, A. A., Fitzhugh, O. G. \& Kunze, F. M. (1950). Y. Pharmacol. 98, 268.

Laug, E. P., Prickett, C. S. \& Kunze, F. M. (1950). Fed. Proc. 9, 294.

Machle, W., Heyroth, F. F. \& Witherup, S. (1944). F. biol. Chem. 153, 551.

Rhodes, A., Sexton, W. A., Spencer, L. G. \& Templeman, W. G. (1950). Research, 3 , 189.

Schweigert, B. S., McBride, B. H. \& Carlson, A. J. (1950). Proc. Soc. exp. Biol., N. Y., $73,427$.

Shaffer, C. B., Critchfield, F. H. \& Carpenter, C. P. (1948). Amer. F. Physiol. 152, 93.

Shaffer, C. B., Critchfield, F. H. \& Nair, J. H. III. (1950). F. Amer. pharm. Ass. 39, 340.

Smyth, H. F. Jr., Carpenter, C. P., Shaffer, C. B., Seaton, J. \& Fischer, L. (1942). J. industr. Hyg. 24,281 .

Smyth, H. F. Jr., Carpenter, C. P. \& Weil, C. S. (1950). F. Amer. pharm. Ass. 39, 349.

Tainter, M. L. (1943). Proc. Soc. exp. Biol., N.Y., 54, 77.

Tauber, O. E. \& Hughes, A. B. (1950). Proc. Soc. exp. Biol., N.Y., 75, 420.

Wang, H., McBride, B. H. \& Schweigert, B. S. (r950). Proc. Soc. exp. Biol., N. Y., 75, 342.

\section{Chemical Additives and Adulterants in Food}

\section{By J. B. M. Coppock, Baking Industries Research Association, Chorleywood, Herts}

\section{Introductory}

The question which it is proposed to discuss is one closely linked with the use of chemical additives in foodstuffs and with the potential adulteration resulting from the use of processing and hygiene aids. It is the evaluation of the functional value of chemicals, which may be suggested for these three methods of use, that will be particularly considered. Thus, only if it can be demonstrated that a chemical has a significant practical effect, i.e. a real functional value, for the purpose proposed does it become necessary to study its pharmacology in relation to the conditions of use suggested.

The discovery of an increasing number of new chemical substances has resulted in the exploration of numerous fields for their use, including the food industry, which finds itself faced with the potential use of chemicals for many purposes, some of which are outlined in Table $\mathrm{r}$. Whatever the particular use of each of these materials may be, there is the possibility that human beings may ingest them in large or small amounts, either by their deliberate inclusion as food additives, or as residues from their use at some stage in food production.

It is clear, therefore, why some of us who have become intimately acquainted with the problem have urged the necessity for precise knowledge of the pharmacology of 